\title{
Strategic urban design from a sustainable tourism perspective: a case study from the city of Guangzhou, China
}

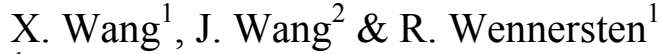 \\ ${ }^{1}$ Industrial Ecology, Royal Institute of Technology, Stockholm, Sweden \\ ${ }^{2}$ School of Architecture, Southeast University, \\ People's Republic of China
}

\begin{abstract}
With the economy booming, the City of Guangzhou sprawled its urban domain quickly. The city was vulnerably struggling on the brink of discretionary control as it lacked the overarching policies for sustainable development. In 2003 the government of Guangzhou initiated a Tourism Planning and Urban Design Consultation to control the development of Seagull Island, which was an agricultural island located in the Pearl River with a population of 20,000 and which is now part of the New-City of Guangzhou. This paper presents the strategic urban design and the design process from a sustainable tourism perspective. To carry out the scheme, a variety of approaches and tools were explored to optimise the design process, which tried to meet social, economic and environmental objectives. The integrated toolbox includes both quantitative and qualitative tools for different design stages, among which working process, SWOT analysis and environmental carrying capacity analysis were thoroughly discussed.

Keywords: strategic urban design, sustainable tourism, integrated toolbox, environmental carrying capacity analysis, SWOT analysis, virtual reality, tourism market analysis.
\end{abstract}

\section{Introduction}

China has been in the international spotlight for years because of its considerable growth in economic and social development. Economic development significantly accelerated the step towards urbanization. The number of the cities 
increased, and the metropolises, such as Beijing and Shanghai, expanded their urban area dramatically due to their nationally or regionally high primacy.

Guangzhou, as the leading city in the Pearl River Delta, has had high economic growth since the 1980s. At the same time, a substantive amount of agriculture land, green spaces and natural forests have been transformed into urban areas every year, which has lead to increasing environmental deterioration and depletion of natural resources (Guangzhou [1]). Local governments, especially at the district level, sometimes short-sightedly make urban development decisions according to market preferences while lacking a holistic sustainable perspective. Consequently, misuse of valuable land and natural resources occurs.

The Government of Guangzhou (GG) tried to develop an efficient plan and scientifically sound policies to develop its physical, economical and social potential, and to protect valuable resources legitimately, and mitigate discretionary or absolutely profit-oriented development. The Master Plan of the city was also adjusted so as to try to cope with the awesome urban sprawl. In 2003 the Guangzhou Urban Planning Bureau (representing GG) initiated a Tourism Planning and Urban Design Consultation as an overarching proposal to control the development of Seagull Island, which was an agricultural island and now part of the New-City of Guangzhou.

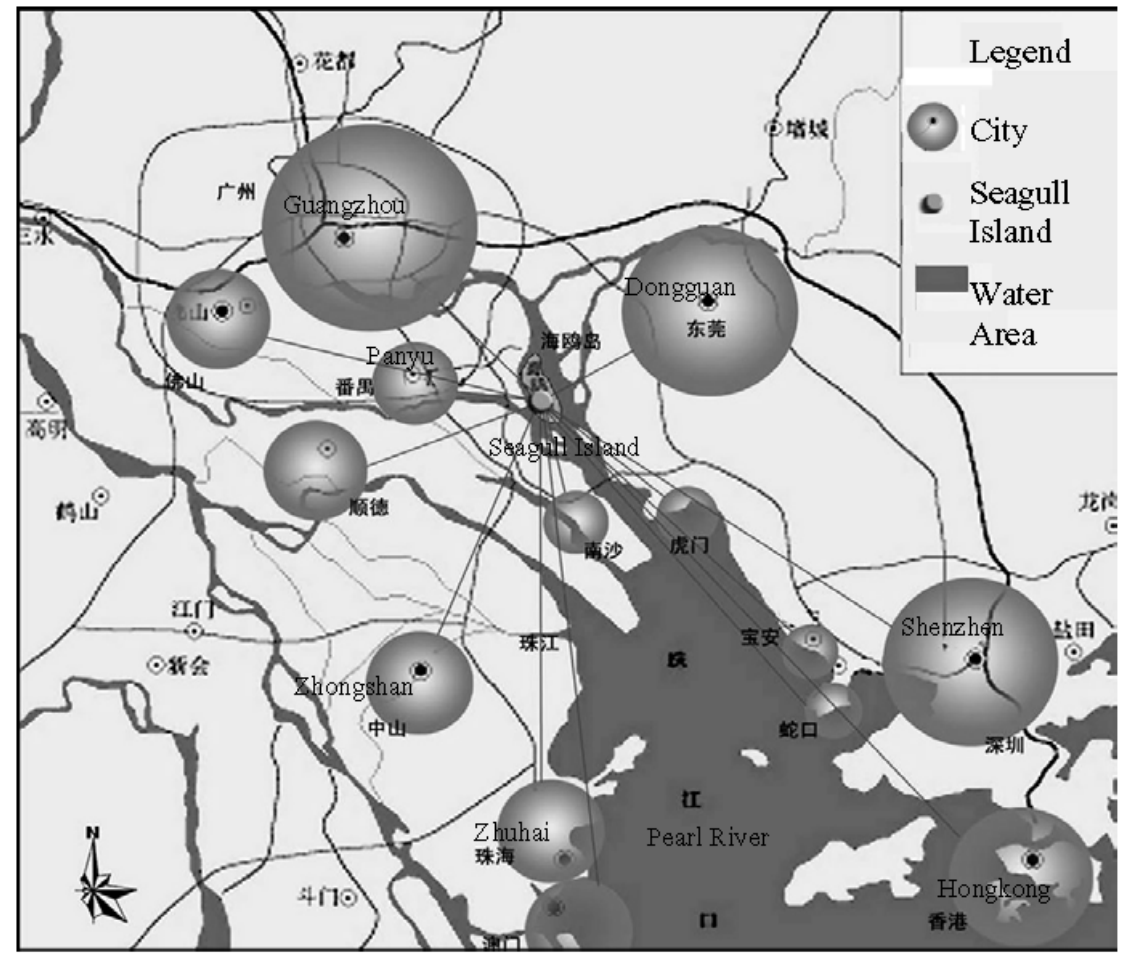

Figure 1: Regional context of Seagull Island in the Pearl River Delta (PRD). 
Another consideration is tourism as a great potential for Seagull Island. The Pearl River Delta (PRD) has become China's most frequented tourist area. Tourism is, after exports and production, one of the most important incomes for this area (Table 1). Within such a growing tourism market, Seagull Island, as the largest island in the Pearl River Delta, presents a great opportunity as an environmental and tourism destination for this area. Its central location between Guangzhou and Hong Kong makes it easily accessible from both urban centres.

Table 1: An analysis of tourism carrying capacity of Guangzhou and the PRD.

\begin{tabular}{|c|c|c|c|c|c|c|}
\hline & \multicolumn{2}{|c|}{ International } & \multicolumn{2}{|c|}{ National } & \multirow[b]{2}{*}{$\begin{array}{c}\text { Total } \\
\text { Number of } \\
\text { Tourists }\end{array}$} & \multirow[b]{2}{*}{$\begin{array}{c}\text { Total } \\
\text { Tourism } \\
\text { Income }\end{array}$} \\
\hline & $\begin{array}{c}\text { Number } \\
\text { of } \\
\text { Tourists }\end{array}$ & $\begin{array}{l}\text { Average } \\
\text { Expenses } \\
\text { / Person }\end{array}$ & $\begin{array}{c}\text { Number of } \\
\text { Tourists }\end{array}$ & $\begin{array}{l}\text { Average } \\
\text { Expenses } \\
\text { / Person }\end{array}$ & & \\
\hline 2002 & $4,739,700$ & $\$ 155$ & $74,364,400$ & $\$ 75$ & $79,104,100$ & $\$ 6,083,012,000$ \\
\hline 2001 & $4,423,700$ & $\$ 150$ & $63,592,600$ & $\$ 75$ & $68,016,300$ & $\$ 5,484,698,700$ \\
\hline 2000 & $4,207,300$ & $\$ 154$ & $57,943,800$ & $\$ 67$ & $62,151,100$ & $\$ 5,008,674,600$ \\
\hline
\end{tabular}

The island itself, 36 square kilometres in area and 20,000 in population, remained relatively unchanged over many years, away from the industrial pollution of the adjacent areas. Two waterways divide the island into three partially connected islands. The local architectural vernacular is in the form of small fishing villages arranged along the edge of a canal system. Farmer's houses have water routes at the front door and fishponds at the back door, creating a unique design vocabulary for the island. The only traffic link to the main land is a 1,400-meter-long Lotus Bridge, which is a two-way road expanding into the island. The water, island and the sense of remoteness from large urbanized areas have made Seagull Island a unique tourism destination.

Current government proposals call for the development of ecological and agricultural tourism with a pastoral setting on the island, trying to fix a win-win situation. Its general objectives were structured as follows (Brief [2]):

- Seagull Island should be developed according to the principles of sustainable development in which resources are properly utilized.

- The island should be developed with a resort orientation, focusing on the regional market.

- The Island should be developed according to the larger metropolitan framework plan that includes open space corridors and development corridors.

- Seagull Island is to be developed as a high-quality, low-density ecological and cultural resort.

- $\quad$ Environmental preservation is to be balanced with new resort development.

- Seagull Island is to be developed in phases, according to a feasible and flexible development approach. 


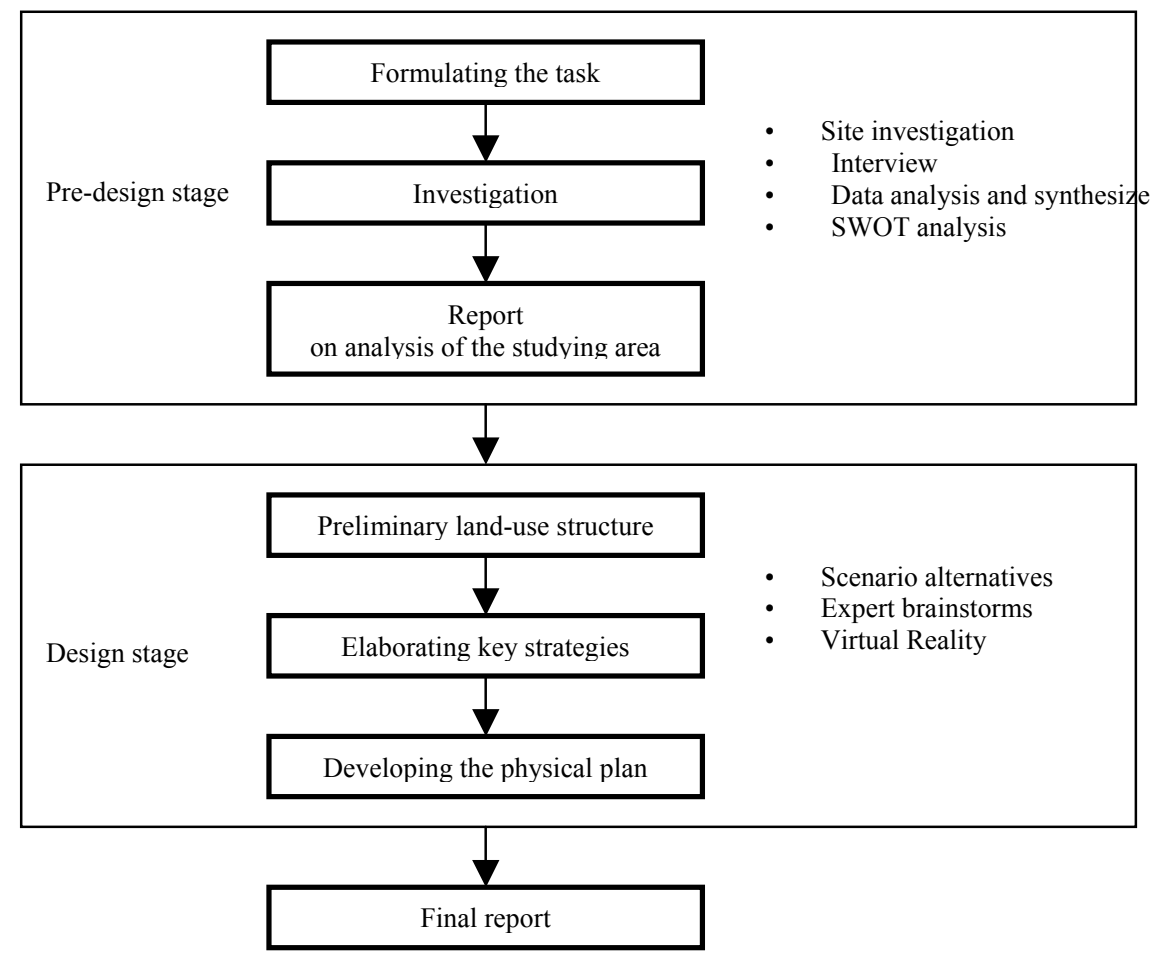

Figure 2: $\quad$ Group working process.

\section{Methodology}

\subsection{Design process}

The final report was required to consist of two parts: a tourism plan and an urban design. The design team accordingly consisted of two groups. As a cooperation team, the tourism plan group was in the USA and the urban design group was in China, which meant that the two groups couldn't meet all the time; consequently it was important that the framework of the process was clear and efficient.

The planning process encompassed a 6-month study period in a sequential process, each step building the results of previous steps (Figure 2).

In the pre-design stage, a work team was organized before visiting the site, which involved experts from related disciplines including urban planners, landscape architects, a GIS analyser, an ecological expert, a marine expert and tourism planners. The team was divided into several groups in studying and analysing the status quo, each holding interviews with different stakeholders and governmental sectors. A subsequent report on the analysis of the study area was presented as a common working basis for the whole team, in which market analysis, heritage conservation analysis, situational analysis, cost-benefit analysis, SWOT analysis, GIS ecological sensitivity analysis and environmental 
capacity analysis were carried out. It was crucially important that an interim report was given to form a common platform for further work for all members of the team.

The Design stage took four months to develop the proposal from general ideas to a physical plan. To develop potential land use structure for the island, the two groups met several times to hold brainstorm sessions. Further design was made individually and synthesized via the Internet and frequent phone conferences.

\subsection{SWOT analysis}

A scan of the internal and external factors is an important part of the strategic planning process, especially when we face a large amount of information from the site and interviews (Urban [3]). The team made a systematic evaluation of the strengths, weaknesses, opportunities, and threats affecting tourism planning and came out with strategy in correspondence to each SWOT analysis (Table 2).

Table 2: $\quad$ Some examples of SWOT analysis.

( $\checkmark$ indicates strategies response to each SWOT analysis)

Strengths

- $\quad$ Unique location within the Pearl River; nothing else like it in the PRD.

$\checkmark \quad$ Conceives of the island as a regional tourism- oriented destination.

- $\quad$ Expansive views of river and agricultural/aquaculture.

$\checkmark \quad$ Views are retained, directed and enhanced.

Weaknesses

- $\quad$ Lack of ecological diversity creates a sterile environment.

$\checkmark \quad$ Plan includes a wetlands restoration and creates potential zones of biodiversity by arrangement of development.

- Depth and breadth of market support and knowledge of/for nature-based tourism.

$\checkmark \quad$ Plan concept is unique and clear in it's form-this aids in the marketing and comprehension of the idea.

\section{Opportunities}

- $\quad$ Nature-based tourism tends to attract high-spend, extended stay tourists.

$\checkmark \quad$ Proposed uses provide a range of high quality opportunities for contact with nature.

- $\quad$ Existing population may offer a "built-in" localized work force.

$\checkmark \quad 20$ year phasing plan allows for employment opportunities in construction, tourism and support services.

\section{Threats}

- $\quad$ Air and water pollution.

$\checkmark \quad$ Proposed uses are environmentally sound, and will not contribute to pollution.

- $\quad$ Competition from other regional nature-based tourism destinations.

$\checkmark \quad$ Plan proposes a natural and authentic environment-based experience that is distinct in the region, and provides market differentiation. 


\subsection{Environmental carrying capacity analysis}

Environmental carrying capacity (ECC) is the ability and adaptability of the environment to provide the physical and non-physical resources humans need, such as the provision of energy and raw materials, the absorption of waste, genetic diversity and fundamental life support services such as climatic regulation [4]. In this project, the ECC is analysed to evaluate the daily capacity of tourists that the island can bear from an environmental point of view and thus get the potential construction magnitude for residential development. The result can be used as a basis for design and for general environmental and economic assessment in the later project stage. ECC can be expressed as

$$
E C C=\frac{W_{\max }+W_{a}}{M}
$$

where $W_{\max }$ denotes the maximum recovery ability by natural metabolism, $\mathrm{M} \mathrm{T}^{-1}$; $W_{a}$ denotes anthropogenic recovery ability, $\mathrm{M} \mathrm{T}^{-1}$; and $M$ is the ability of anthropogenic intervention to the environment per capita, $\mathrm{M} \mathrm{T}^{-1} \mathrm{H}^{-1}$.

The ECC could have diverse values depending on the indicators we use. For example, the results from the ECC of air, the ECC of water, and the local treatment ability for solid waste differ from each other. The minimum of the calculation can be adopted as the final ECC value.

The report of the project calculates ECC by Biochemical Oxygen Demand (BOD5) of water, oxygen needed, carbon dioxide and solid waste produced, total suspended particulate matter etc. This paper presents only the results with respect to the BOD5 of water. First, it is assumed that rainwater (the natural water source of the island) is pure water and the local BOD5 standard is $4 \times 10^{-3}$ $\mathrm{kg} / \mathrm{m}^{3}$ (according to the official water standard III), which means the carrying capacity of organic pollution of water. Thus, the yearly recovery ability by natural metabolism, $W$, reads

$$
W=R S B
$$

where $R$ stands for Yearly Rainwater, $S$ the area of the island, and $B$ the local BOD5 standard.

Subsequently, the daily capacity of tourists, $Q$, can be given by

$$
Q=\frac{W}{p\left(1-\eta_{1} \eta_{2}\right)}-L
$$

where $Q$ denotes the daily capacity of tourists, and $p$ is the BOD5 produced as waste per capita per year $(14.6 \mathrm{~kg}), \eta_{1}$ is the removal efficiency of BOD5, $\eta_{2}$ is the treatment efficiency of wastewater and $\mathrm{L}$ is the number of local inhabitants.

In the project, $R=1.5 \mathrm{~m}, S=3.6 \times 107 \mathrm{~m}^{2}$, which gives $W=2.16 \times 105 \mathrm{~kg} / \mathrm{yr}$. Thus, if we choose $\eta_{1}=90 \%, \eta_{2}=90 \%$ (both are typical values) and $L=30,000$ (the planned number of local inhabitants), the capacity of tourists $Q$ would be 48,000 persons.

This preliminary prediction of daily capacity of tourists would work as a reference for further design and also be used as basic data for physical planning and environmental policy making. 


\subsection{Comparative case study}

As a consultant competition project, it was hard to develop a sound physical plan based on limited data in a given period. The challenge was unique for the working team. Any decision would be arbitrary and hasty if it lacked the full communication with the stakeholders. However, further data collection and analysis could be implemented after the first consultancy period. In this sense, case study played an instrumental role for planners in making decisions between alternatives and also drew a picture of the future scenario for the stakeholders. A comprehensive review of tourism planning for the islands was presented as an appendix in the final report.

When the working team decided the planned number of tourists, a tourism resource analysis was made based on regional tourism statistics, but no data indicated any specific island. A reference island called Heart of Yangtze River with comparative area and functions would work to estimate the source and the number of tourists, daily expenses etc.

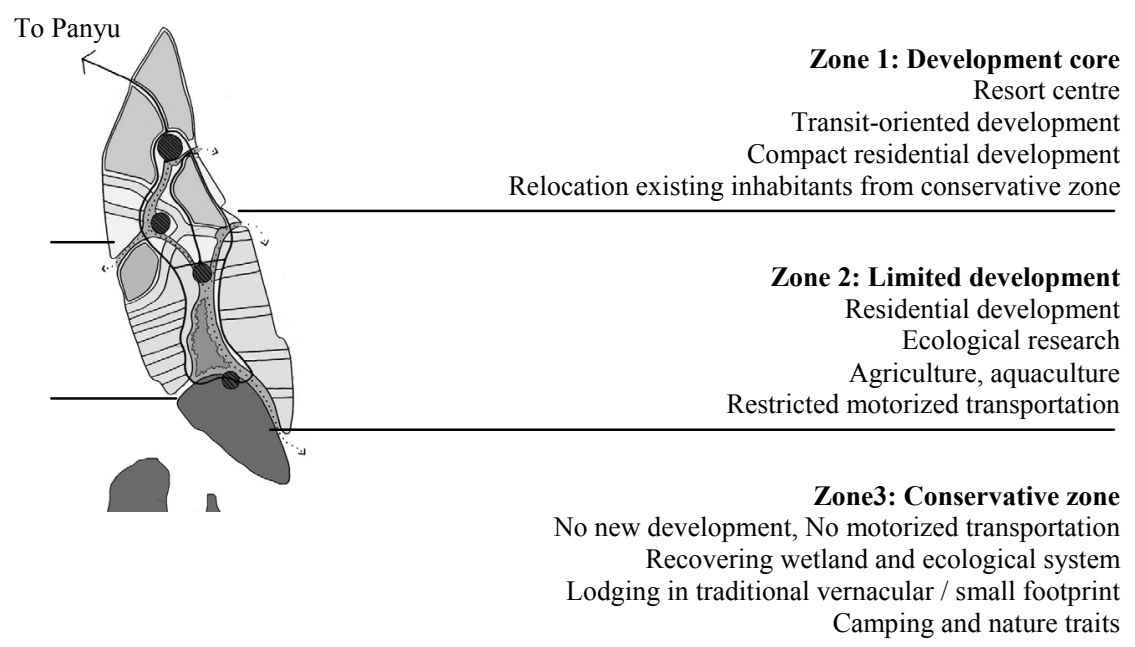

Figure 3: Concept of general structure.

\section{Plan summary}

Tourism development is a double bladed sword between real estate development (including tourism facility construction) and ecological system recovery, both of which also work as marketing attractions. The overall aim of sustainable tourism planning is to achieve a trade-off between tourism development and environmental sustainability both in the near future and in the long run, with equitable and environmentally balanced and socially cohesive economic development. 


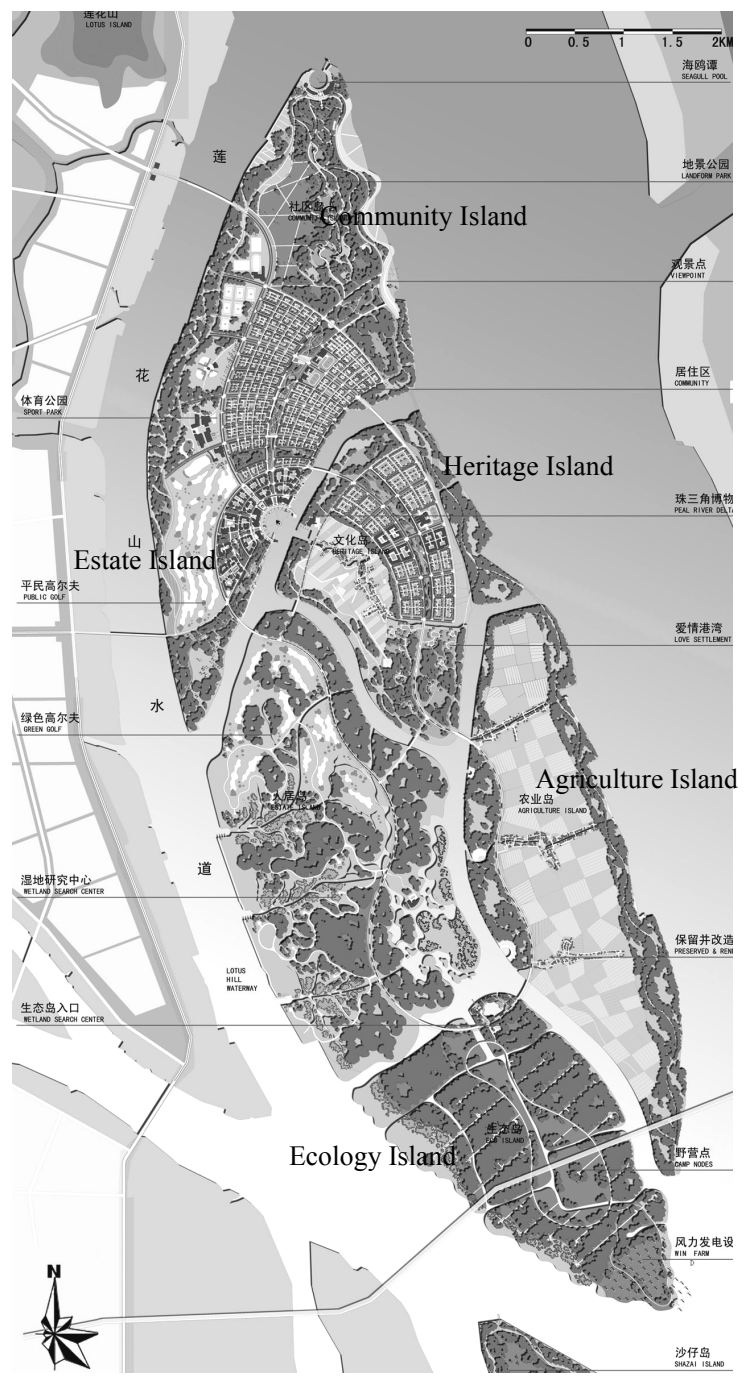

Figure 4: Master plan.

The physical plan divides Seagull Island into five smaller sub-islands, based upon the natural form of the existing waterways and drainage patterns. Each island is unique; development density varies from one island to the next, as do types of housing, recreation, attractions, lifestyle, transportation, and ecological sensitivity. Development is most intense on Community Island to the north, and decreases towards Ecology Island to the south. Community Island is proposed as being the most developed of Seagull Island's sub-islands, accommodating a town centre sited around a marina, a medium-density mixed-use residential district, 
and sports and recreation complexes. Heritage Island will become mainly a resettlement district, with a cultural/folk village and floating market as the main attractions. Estate Island is envisioned as having a very low-density residential product amidst sprawling marshlands, canals, and wooded areas. A private "green" golf course that incorporates sustainable concepts exclusively will serve the residents of Seagull Island, while a Wetland Research Institute is anticipated to be a tourist attraction as well as an educational and research centre. Agricultural Island is to remain relatively unchanged, preserving the settlement character, agricultural fields, and natural landscape feeling of Seagull Island. Agro-tourism will be promoted on this sub-island, encouraging eco-friendly activities among the existing population. Finally, Ecology Island will undergo little or no development, serving primarily as a recreation and eco-tourism destination, with lodges and campsites scattered in various unique landscape settings.

The pressure of rural urbanization will emerge with the steps towards tourism development. Traditionally, farming and the harvesting of seafood are the main incomes of local peasants. The plan commits itself to retaining agricultural heritage and local lifestyle. Local farms will serve as a model for how humans should live in concert with nature, creating a destination in which conservation measures, tourism and economic vitality are practiced holistically. Moreover, localization of labour will be a basic strategy for the local employment market.

A strategic plan for a sustainable development is based on three dimensions: economic, social, and environmental levels. Economic feasibility is substantial for the physical implementation of the plan, which also works as the catalyst to meet social and environmental objectives. A 20-year implementing strategy with four phases is proposed to develop the island. Each phase is to be a 5-year plan, and a mix of public and private ventures is proposed, while retaining a balance of revenue and non-revenue uses.

A bunch of environmental strategies are also proposed in the final report, including a green planning scheme and a series of alternative technologies and methods as environmental strategies.

\section{Conclusion and discussion}

The plan sets out a vision of urban design for sustainable tourism in a Chinese context.

- A strategic urban design based on tourism plan would be instrumental to prevent discretionary and profit-oriented development, serving as a strategy to protect valuable land resources, amenity space and natural reserves of biodiversity.

- In the design process, a set of analysis methods from an economic or environmental perspective established a scientific basis to pin down strategies and develop a physical plan.

- A team with a diversity of experts from relative fields could come up with vivid ideas from interactive brainstorms and effective collaboration. 
Nevertheless, the planning process also revealed some pitfalls as follows.

- Lack of a database is the main hindrance to reach more precise estimations of the number of tourists, the corresponding tourism market and the potential environmental impact. Although several analysis methods were applied to help and support the planning process, in-depth analysis was still insufficient due to lacking of specific data, limited competition period and funding. From another angle, it was also potentially necessary to develop practical methods for decision making in a preliminary planning period, especially for planners and designers, which should be flexible for different users and for different design stages.

- In an initial consultancy stage as such, planning cannot represent well the interests of different governmental sectors and stakeholders. There was not the time for them to stack up against each other to strive for individual interests. The interviews were not so critical because sometimes we could not reach the key persons in some governmental sectors.

- A physical urban design is not essential in such an initial stage, while a report with concrete analysis and a rigorous proposal is more important. But the decision-makers and the public need a visualized picture to raise awareness of what could happen in the future; thus such a physical urban design worked as it was more public oriented than a real project.

- $\quad$ Long-distance cooperation was possible for an urban design project with limited meetings, connecting from the Internet, FTP-resource sharing, telephone (or even visual) conferences, etc. But it was also time-consuming for file transfer, waiting for feedback and making an appointment or telephone conference. Face-to-face communication is still un-substitutable for its interactivity and stimulating atmosphere between people, especially for the first stage.

\section{Acknowledgement}

This consultant project was carried out by the School of Architecture, Southeast University, China, cooperating with SASAKI co. USA in 2002. Prof. Jianguo Wang was the principal for the whole project.

\section{References}

[1] 广州政府工作报告, 2002.

[2] Technical Document Project Brief for Seagull Island planning, Guangzhou Urban Planning Bureau, 2003.

[3] Urban Design For Sustainability, Final Report to the European Union Expert Group on the Urban Environment, 2004. http:/europa.eu.int /comm/environment/urban/pdf/0404final_report.pdf (Visited 2005-05-09).

[4] Randall Thomas, Sustainable Urban Design: An Environmental Approach, Landon and New York: Spon Press, 2003. 